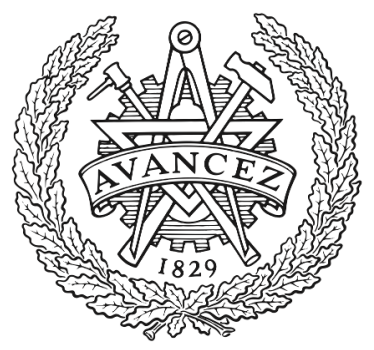

CHALMERS

UNIVERSITY OF TECHNOLOGY

\title{
Adapting discrete goods supply chains to support mass customisation of pharmaceutical products
}

Downloaded from: https://research.chalmers.se, 2023-04-26 14:27 UTC

Citation for the original published paper (version of record):

Siiskonen, M., Mortensen, N., Malmqvist, J. et al (2021). Adapting discrete goods supply chains to support mass customisation of pharmaceutical products. Concurrent Engineering Research and Applications, 29(4): 309-327. http://dx.doi.org/10.1177/1063293X211002169

N.B. When citing this work, cite the original published paper. 


\title{
Adapting discrete goods supply chains to support mass customisation of pharmaceutical products
}

Concurrent Engineering: Research and Applications $1-19$

(C) The Author(s) 2021 Article reuse guidelines: sagepub.com/journals-permissions DOI: $10.1 \mid 77 / 1063293 \times 211002169$ journals.sagepub.com/home/cer

\author{
Maria Siiskonen' ${ }^{(0)}$, Niels Henrik Mortensen ${ }^{2}$, Johan Malmqvist ${ }^{\prime}(1)$ and \\ Staffan Folestad ${ }^{3}$
}

\begin{abstract}
Emerging research within the field of personalised medicines has aimed to enhance patient treatment through the use of pharmaceutical products that are customised to the individual needs and preferences of the patient. The currently dominant production platforms of pharmaceutical products, however, regard a mass production paradigm and are thus unfeasible for the production and provision of personalised medicines. The production platforms are not designed or are intended for a customisation context. Operating such a context with the current supply chain entails challenges such as increasing costs, time to patient and efforts in quality assurance activities. To address these challenges, this paper presents four reconfigured pharmaceutical supply chain designs. A qualitative operational performance assessment elicits the strengths and weaknesses of the respective supply chain design operating in a customisation context. The results suggest that a later point of variegation, that is, the point in the supply chain where the final customisation is achieved, can relieve the operational effort of the stakeholders in the supply chain while providing the benefits of personalised medicines, that is, an enhanced treatment outcome of the patient. A trade-off remains, however, between the supply chain's decreased operational effort and degree of necessary reconfigurations, such as introducing new functions to stakeholder operation, reallocating activities to other stakeholders or educating stakeholders.
\end{abstract}

\section{Keywords}

mass customisation, personalised medicines, pharmaceutical supply chain design, supply chain reconfiguration, integrated design

\section{Introduction}

An emerging patient-centric approach to treatment provision has the core purpose of enhancing the treatment outcome of the patient, emphasising the treatment's safety and effectiveness (Ahmed et al., 2016; Meyer, 2004). Personalised medicines, that is, treatments customised to the individual needs and preferences of the patient are widely researched with patient-centricity in mind (Crommelin et al., 2011).

Recent pharmacological research supports a shift towards a paradigm of personalised medicines, thereby providing tools to map patients' biological attributes. Patient-centric treatments are established by translating their biological, environmental and behavioural attributes into treatment design parameters (Govender et al., 2020a, 2020b). The current pharmaceutical products and production system is, however, neither designed nor intended for personalised medicines. The product design still embraces a one-size-fits-all design, as mass production in a batch manner permeates the operational mode of pharmaceutical production to produce large volumes of identical product variants (Wilson, 2016). A transition towards pharmaceutical product customisation implies decreased production

\footnotetext{
'Department of Industrial and Materials Science, Chalmers University of Technology, Gothenburg, Sweden

${ }^{2}$ Department of Mechanical Engineering, Technical University of

Denmark, Kongens Lyngby, Denmark

${ }^{3}$ Pharmaceutical Technology and Development, AstraZeneca

Gothenburg, Mölndal, Sweden

Corresponding author:

Maria Siiskonen, Chalmers University of Technology, Hörsalsvägen 7A,

Gothenburg 4I2 96, Sweden.

Email: maria.siiskonen@chalmers.se
} 
volumes, increased product variants and design complexity - the current production platforms' technical capability and economic feasibility is surpassed (Govender et al., 2020a; Siiskonen et al., 2020; Wilson, 2016). Without feasible production and provision, customised pharmaceutical products cannot reach the patient, thereby preventing enhancement of the treatment outcome.

In the pharmaceutical product context, mass customisation is discussed as a solution for a paradigm of customised pharmaceutical products, meaning 'designing, producing and distributing customised pharmaceutical products in an economically feasible manner' (Govender et al., 2020a); however, there is a lack of extensive mass customisation discussions in a pharmaceutical product context in the literature. Past studies considered patient-centric product design by introducing novel technologies such as additive manufacturing (e.g. Goyanes et al., 2015; Norman et al., 2017), but they lacked technical and economic realisability or strategic product provision. When conducting product improvement tasks, however, it is important to consider an integrated approach to product customisation as well as feasible production and provision (Prasad, 2016). Sequential product development runs a risk of late and costly changes propagating from product design (Landahl et al., 2020). A few notable publications discuss production system design to manage the growing complexity of the product portfolio as a consequence of product customisation (i.e. decreasing product volumes and increasing product variants), for example, Srai et al. (2015), O'Connor et al. (2016) and Harrington et al. (2016). These studies consider refined mass production by proposing novel technologies enhancing the efficiency of manufacturing while preserving current production platform design as well as a one-size-fits-all product design and omitting the discussion of product provision.

To the best of our knowledge, there is an absence of system-level analysis of current pharmaceutical supply chain designs operating in a customisation context beyond point-based solutions to product or production system design. Current approaches have either considered patient-centric product design for the optimization of individual treatment (Goyanes et al., 2015; Norman et al., 2017), failing to incorporate any consequential analysis on the technical and economic feasibility from wider production and provision perspective. On the other hand, the increasing volume/variety complexity challenge in pharmaceutical production has been addressed by introducing novel technologies into production optimization (Harrington et al., 2016; O'Connor et al., 2016; Srai et al., 2015). These studies have rather considered a refined mass production paradigm still considering a one-size-fits-all product design and disregarding a wider supply chain perspective and product provision. Product improvement tasks require concurrent design to eliminate risks of late and costly changes propagating from product design to respective domains (Landahl et al., 2020; Prasad, 2016), thus, a mass customisation paradigm for pharmaceutical products requires integrated approaches to patient-centric product design, production system design and feasible product provision.

This study is guided by the following research questions: RQ1 is formulated as: What are the operational weaknesses of the current pharmaceutical supply chain design when operated in a pharmaceutical product customisation context? A system-level end-to-end assessment of the currently operating pharmaceutical supply chain in a customisation context is provided and operational criteria are collected for a performance assessment to elicit weaknesses. Thus, RQ2 is: Which operational performance criteria can be used to assess the performance of the pharmaceutical supply chain operating in a customisation context? The weaknesses of the currently operating supply chain in a customisation context are addressed, and RQ3 is thus formulated as: How can the pharmaceutical supply chain be reconfigured to address the operational weaknesses of the currently operating pharmaceutical supply chain? This question suggests reconfigured pharmaceutical supply chain designs operating in the customisation context and assesses their performance.

The remainder of the paper is organised as follows: Section "Research approach" describes the research approach, scoping and delimitations of the study. A state of the art review of essential concepts is provided in Section "State of the art". Section "The pharmaceutical supply chain" details the pharmaceutical supply chain. Section "Results" presents the results of the study which are discussed in Section "Discussion" providing an answer to each research question as well as discussing limitations of this study and proposing further research to address these limitations. Section "Conclusions and future work" concludes the findings and highlights opportunities for future research.

\section{Research approach}

The industrial challenge described in the Introductionsection, that is, the currently dominating massproduction operating mode for pharmaceutical products is challenging a paradigm of personalised medicines, constituted the starting point of this research. Key literature on current pharmaceutical production and its challenges in a customisation context was scrutinised to establish a research gap, that is, the lack of end-to-end system-level analysis of pharmaceutical production in a customisation context (e.g. Ahmed et al., 2016; Govender et al., 2020a; Harrington et al., 2016; 
O'Connor et al., 2016; Siiskonen et al., 2020; Srai et al., 2015; Wilson, 2016).

The currently operating pharmaceutical supply chain was mapped, the as-is design of the supply chain, using literature describing this (e.g. Aitken, 2016; DerecquePois, 2010; Olson, n.d.; Savage et al., 2006; Shah, 2004). An analytical assessment of operational consequences was performed on the as-is design, when operating this in a customisation context, to further verify the industrial challenge posed at the beginning and to elicit the weaknesses of operating the $a s-i s$ design in a customisation context. For the assessment, a set of operational performance criteria was collected from the literature concerning current pharmaceutical production in a customisation context. Due to the scarcity of this literature, the literature on mass customisation as well as product portfolio complexity and operational performance in industrial contexts were reviewed to complement the list of criteria. For the initial collection of performance criteria, the following studies were used as guidance (Govender et al., 2020a; Price Waterhouse Coopers, 2011; Rantanen and Khinast, 2015; Shah, 2004; Stäblein et al., 2010; Trattner et al., 2019; Wilson, 2016). The initial set of criteria was, furthermore, discussed with a group of industrial practitioners and refined accordingly. As the operational performance assessment method, the concept screening matrix by Ulrich and Eppinger (2012) was used.

Novel reconfigurations to the pharmaceutical supply chain were then proposed to address the operational weaknesses of the as-is design in a customisation context. To establish reconfigurations, successful business models operating in a mass customisation paradigm or managing complex product portfolios were explored. Search terms such as 'successful business models' and 'customisation' and 'large product variety' were used to explore these business models. As a search engine the University library was used, and further, to expand the scope beyond academic research Google search was used. Due to the lack of supply chain models operating in a pharmaceutical customisation context, the focus was on supply chains of discrete goods. As selection criteria, business models with final assembly occurring at various phases of the supply chain was used to inspire to a large span of design variations, that is, applying the mass customisation principle postponement. Business models providing inspiration incorporated the ones operated by Walmart Inc., the restaurant franchise Subway and the computer technology company Dell (Bhasin, 2019a, 2019b; Lutz, 2014).

Theory synthesisation occurred by the means of adapting the studied business models into the pharmaceutical supply chain context, that is, proposing the supply of pharmaceutical products according to the business models explored but within the context of a pharmaceutical supply chain regarding supply chain actors, activities, product nature and so forth. These models were further refined after discussing these models with a group of industrial practitioners resulting in final reconfigurations of the pharmaceutical supply chain.

Finally, the operational performance of these reconfigured supply chain designs was assessed by using the same set of performance criteria as for assessing the performance of the as-is design. Likewise, the concept screening matrix by Ulrich and Eppinger (2012) was used as a method for performance assessment.

\section{Scoping and delimitations}

This section clarifies the assumptions and delimitations before conducting the study.

Pharmaceutical product customisation refers to designing and producing personalised medicines, and thus the terms customised pharmaceutical products and personalised medicines are used interchangeably. This study only considers customisation of the physical product from a technical perspective, excluding customised patient caretaking approaches.

Pharmaceutical products regard prescription products (both brand-name and generic drugs) and embrace a solid oral dosage form, specifically a tablet design. Patient-centric product design is not explicitly studied but rather, the consequence of these designs on the operation of the pharmaceutical supply chain is studied, that is, the growing complexity of the product portfolio on supply chain management. This paper will not study the concept of complexity per se, but rather use the term when addressing the growing product variety - product volume complexity of the product portfolio.

Explicit knowledge on the absolute level of customisation for pharmaceutical products cannot be found. In this study, the level of customisation of a prescription acquired by the patient resembles a pre-assembled pill organiser. This paper's supply chain scenarios aimed at operating in a customisation context will embrace the same final product variety. Furthermore, in any customisation scenario, customer interference with the treatment before administration is assumed to be nonexistent and outside the scope. Furthermore, this study considers no intravariability of patient prescriptions over time, meaning that patient prescriptions do not change over time since no longer time periods are considered in this study.

This paper primarily considers the supply chain actors physically in contact with the pharmaceutical product, which includes the secondary manufacturer, wholesaler, retailer and customer. The primary manufacturer, the producer of the raw materials for the pharmaceutical product is disregarded in this study. The 
assumption is that no design changes are made on a molecular level, and hence the primary production might operate as-is in all scenarios analysed in this study.

The customer group is solely represented by the patient; however, the healthcare system regards a complex network in which society, a country's healthcare system, authorities, etc. can be considered customers. Healthcare system operation exceeds the scope of this study due to the lack of a global healthcare system, and thus decisions regarding reconfiguration must be made on a local level integrated to any global-level decisions. Compliance to the regulatory framework will be incorporated when assessing the performance of the supply chain design. The regulatory framework is assumed to be static and the consequences of compliance in a customisation context are assessed. For ongoing research discusses the reshaping of regulatory compliance approaches for a paradigm of personalised medicines the reader is referred to, for example, Rantanen and Khinast (2015).

\section{State of the art}

This section reviews essential literature for the study. A brief description of personalised medicines is given along with the challenges of personalised medicines in a currently operating pharmaceutical production paradigm. The consequential complexity challenge of a paradigm of personalised medicines is discussed and finally, the topic of mass customisation as a probable remedy for the complexity challenge is addressed. This section is concluded by clarifying research gaps addressed in this study, based on the before reviewed literature.

\section{Personalised medicines}

Personalised medicines refer to treatments, that is, the dosage form such as tablets or capsules, that are customised to the individual needs and preferences of the patient (Govender et al., 2020a, 2020b). The core purpose of personalised medicines is to enhance the treatment outcome of the patient, that is, delivering safe and effective treatments (Ahmed et al., 2016).

\section{The current production paradigm of pharmaceutical products}

Despite the emerging personalised medicines research, a mass production-dominated paradigm of pharmaceutical products challenges the wider establishment of personalised medicines. A mass production (MP) paradigm implies a batch-based production of pharmaceutical products embracing a one-size-fits-all design. This permeates the treatment prescription procedure which commonly provides the physician with the choice between 4 and 6 product variants. This does not optimise the patient's therapeutic outcome, but it has been argued that increasing the number of product variants is not economically feasible production-wise (Wilson, 2016).

An MP paradigm of pharmaceutical products arguably manages a complex product portfolio. To illustrate this product portfolio complexity, Wilson (2016) exemplifies that manufacturers might produce $10-40$ variants of a single drug substance when factoring not only various dose strengths but also product formulations (e.g. solid or liquid). When packaging the products, the number of variants is increased 10 -fold since manufacturers serve markets in several countries, which pose different regulations and rules upon the final product variant (drug product in packaging) creating variety regarding packaging. Patients are thus divided into large segments to achieve economies of scale. Govender et al. (2020a) conclude that current manufacturing platforms are insufficient concerning affordability if production volumes per variant are decreased.

\section{Approaches to personalised medicines}

Research within the field of personalised medicines has primarily considered technical solutions for patientcentric product design or efficient management of the consequential growing complexity of the product portfolio within manufacturing. The growing complexity challenge has been addressed by, for example, Srai et al. (2015), O'Connor et al. (2016) and Harrington et al. (2016), with the focus to introduce novel technologies into production, specifically continuous production. These studies failed to consider a complete end-to-end level assessment incorporating distribution and patient provision.

\section{Complexity as a consequence of customisation}

Customisation, and the resulting increase in product variants, has a crucial consequence on complexity as pointed out by Stäblein (2010). An increasing number of product variants require an increasing number of product designs, parts as well as manufacturing processes for these parts and products, not to disregard the management of these parts and products throughout the supply chain, any resources required to operate the processes, to design the products and create the final variety in products and so forth. These are a few reasons for the growing complexity of a larger product variety and thus, increasing the difficulty of managing the growing product variety (Kvist, 2010). 
Concurrency in design. Kvist (2010) further emphasized the importance in clarifying the connections of the product design and the remaining phases of the product lifecycle and various approaches to express these interactions have been proposed by for example, Kvist (2010) and Prasad (2016). Concurrent activities have regularly been adopted to improve performance. Landahl et al. (2020) proposed an approach to concurrency in product design tasks by integrating dynamic product and production modelling to eliminate the risk of late and costly product design changes propagating to production in sequential product development. Hence, the customisation of products for product improvement, increasing the final complexity of the overall product portfolio, is crucial to connect to the operational aspects that are affected from this change on phases beyond the product design domain.

Complexity and operational performance. Identifying connections enabling the analysis of the consequences of product portfolio complexity on the operational performance of phases beyond product design is crucial to enable an end-to-end analysis. Complexity and operational performance have been discussed, for example by Stäblein et al. (2010) where the influence of complexity on manufacturing costs, lead times and so forth was presented. Trattner et al. (2019) performed a systematic literature review on the consequences of product complexity on operational performance concluding that product complexity has not only an unfavourable effect on cost and time but also the quality and delivery reliability, even though less clearly. Trattner et al. (2019) also provided a discussion regarding the complexity of the product portfolio and the increased risk of errors in operations, product quality issues as well as increasing errors from manual handling.

Mass customisation: A remedy of the growing complexity. Mass customisation (MC) in a pharmaceutical context has been hypothesised as a solution to enable the commercialisation of personalised medicines to mitigate complexity. Hu (2013) discussed three principles of MC: modular product architectures, reconfigurable manufacturing systems and postponement or delaying differentiation, each of which supports managing or mitigating complexity arising from the customisation demand of products. According to Kvist (2010), the key to effective production of product variety is to postpone the differentiation to the latest possible point in the supply chain hence, the complexity mitigation strategy focused on in this paper is postponement.

\section{Gaps in the literature}

There is, to the best of our knowledge, a lack of system-level, end-to-end approaches assessing the consequences of supply chain operations in a pharmaceutical product customisation context. An end-to-end assessment is required to understand the consequences of transition towards a personalised medicines paradigm, where the number of product variants is substantially increasing. This paper provides an understanding of the consequences of operational performance when introducing a customised product portfolio into a currently operating pharmaceutical supply chain. Furthermore, there is a lack of approaches addressing the operational weaknesses of a currently operating supply chain in a customisation context and thus, this paper aims at addressing this gap by the usage of the MC principle of postponement and suggesting reconfigurations to the pharmaceutical supply chain by moving the point of variegation, that is, the point in the supply chain where the parts become dedicated to a product, to provide remedy for the posed difficulties in operation.

\section{The pharmaceutical supply chain}

The main supply chain actors of the current pharmaceutical supply chain, called as-is design throughout this paper, include the secondary manufacturer, wholesaler, retailer (pharmacy), physician and patient (Aitken, 2016; Olson, n.d.; Savage et al., 2006; Shah, 2004). Figure 1 displays the design of the pharmaceutical supply chain and a detailed description of the supply chain actors, the transformation of the pharmaceutical product throughout the supply chain as well as the main functions of the actors - contributing to the transformation of the product follows.

The upper bar, in Figure 1, displaying the supply chain actors illustrates their communication path as well as the physical journey of the pharmaceutical product throughout the chain. The physician is not placed in the upper bar since the physician is not physically in contact with the product. The transformation of the pharmaceutical product is described by the ellipses labelled A to J. Figure 2 aims at clarifying the nature of product variety throughout the transformation phases - limited to crucial phases of the product transformation. Drug product (DP) refers to the finalised dosage form, that is, the tablet, while FDP denotes final drug product, referring to market-ready DPs, that is, packaged and labelled accordingly. The activities transforming the product are described in the rectangles and numbered within parenthesis, such as (X.X), according to the actor performing the activity, which follows the 


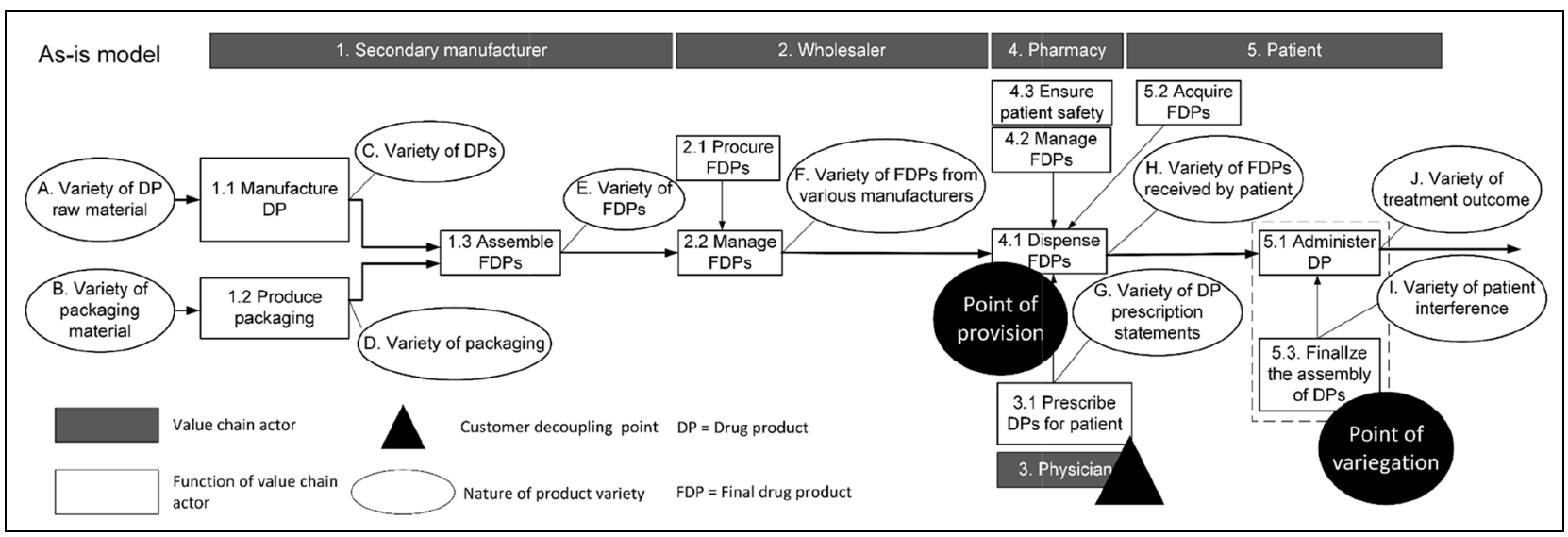

Figure I. The as-is scenario of the pharmaceutical supply chain illustrating the path of the product transformation throughout it.

numbering of Figure 1. The nature of the product resulting from the transformation performed by a supply chain actor is described and denoted within parenthesis $(\mathrm{X})$ following the labelling in Figure 1.

The pharmaceutical supply chain is only regarded downstream from the secondary manufacturer, which transforms raw materials into FDPs (Savage et al., 2006; Shah, 2004). This secondary manufacturer's primary function is divided into three activities, firstly manufacture DP (1.1), where raw materials (A), that is, active and non-active ingredients are converted into administrable tablets, DPs. Tablets can vary regarding contents, size, shape, etc. (C) and are packed into intermediate packaging for transfer to the assembly process. The second activity produce packaging (1.2), converts packaging material (B) into primary, secondary and tertiary packaging (D). Primary packaging is the blister pack sealing the tablets. Secondary packaging collects the blister packs into a market-ready packaging incorporating information leaflets about the DP. The tertiary packaging is aimed for bulk packaging enabling convenient management of the products downstream the supply chain (Savage et al., 2006). These package types require printing and labelling to identify and inform about the DP according to manufacturer branding and country-specific requirements (Savage et al., 2006). Packaging DPs into respective packaging occurs during activity (1.3) assemble FDPs, resulting thus in FDPs. In Figure 2, for example for product variety E a five-point star is placed by the FDPs. This star appears to the right of the labelling of product variants 1,2 and $\mathrm{M}$ to mark the variety due to country-specific requirements. This means that various packaging is produced for the same DP (Shah, 2004).
The FDPs (E) are purchased by the wholesaler from various manufacturers, that is, procure FDPs (2.1). The wholesaler bundles and resells the FDPs (F) to pharmacies (Derecque-Pois, 2010; Shah, 2004). Product variety is created from various manufacturers not to disregard identical DPs acquired from various manufacturers (European Alliance for Access to Safe Medicines, n.d.; Olson, n.d.; Shah, 2004). This is illustrated in Figure 1 by a matrix displaying 1 to $\mathrm{M}$ product variants from $\mathrm{A}$ to $\mathrm{N}$ manufacturers. The distinction between manufacturers is achieved by colour coding the symbol for labels and information leaflets and so forth. The wholesaler activities are compiled under the expression manage FDPs (2.2).

The physician function in this study is limited to the activity of prescribing treatments for patients (3.1) from making a diagnosis of the patient, resulting in a prescription statement $(G)$ communicated to the pharmacy. This describes which DPs the patient shall receive.

The patient acquires their prescription at the pharmacy, whose primary function is to provide the patient with the FDPs (F) according to the physician's prescription statement $(\mathrm{G})$. This function incorporated the activities: dispense FDPs (4.1), that is, dispensing FDPs to the patient; manage FDPs (4.2) which includes activities from procuring FDPs to stocking products to respond to uncertain demand for product variants (Aitken, 2016; Olson, n.d.). Furthermore, ensure patient safety (4.3) is a primary function of a pharmacist to ensure the safety of a treatment which includes activities of correcting prescription errors made by the physician, counselling the patient on side effects and the treatment's dosing procedure and so forth (European 


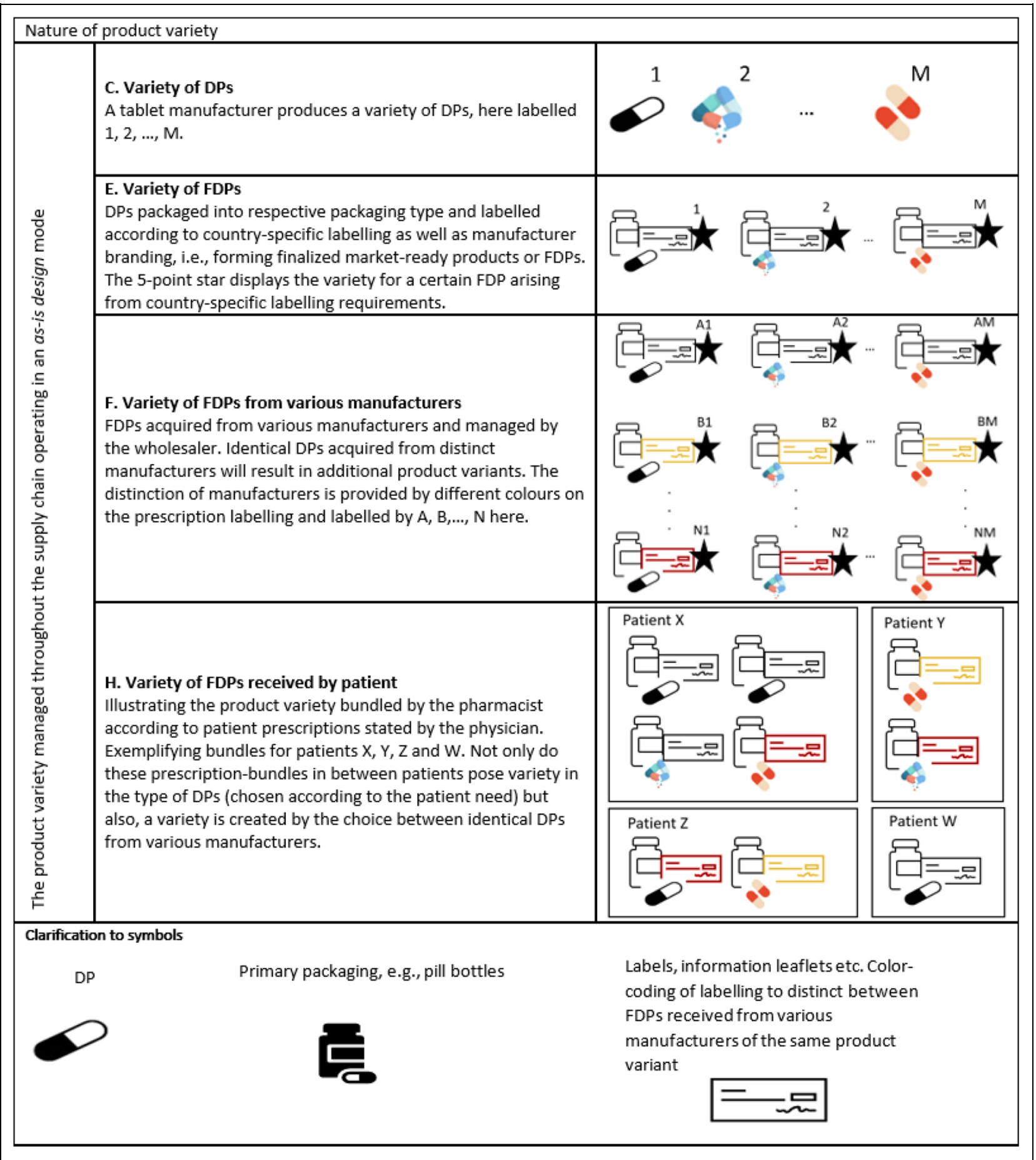

Figure 2. Illustrations of the nature of the product variety for a few crucial supply chain phases.

Alliance for Access to Safe Medicines, n.d.; Olson, n.d.). Overall, the nature of product variety when received by the patient $(\mathrm{H})$ is a function of the product varieties $(F)$ and $(G)$ as well as any variety created by the pharmacist when correcting prescription errors.
The patient activities include acquire FDPs (5.2), this study expects the patient to acquire the prescription at the pharmacy, and administer DP (5.1), which refers to swallowing the tablet, hence, inducing a treatment outcome $(\mathrm{J})$ of the patient. Furthermore, the patient might 


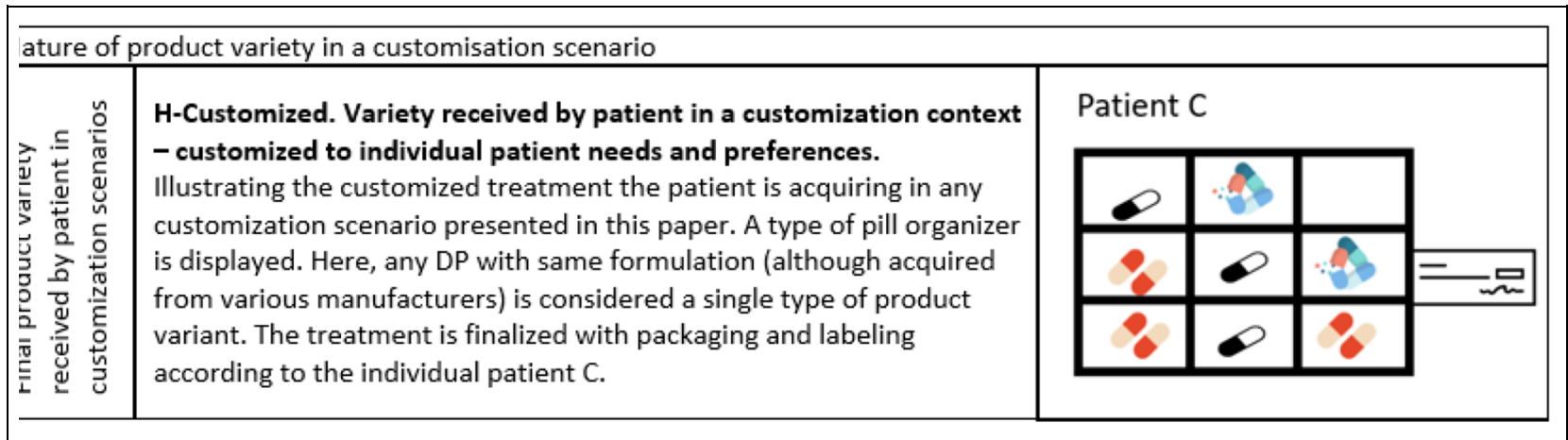

Figure 3. The nature of product variety provided to the patient in a paradigm of personalised medicines.

need to interfere with the treatment before administration, for example, splitting tablets, administering multiple tablets or combining treatment with food (Govender et al., 2020a; Verrue et al., 2011). This interfering activity is called finalise the assembly of DPs (5.3). Thus, the final variety in treatment outcome $(\mathrm{J})$ is affected by the variety of FDPs received at the pharmacy $(\mathrm{H})$ and patient interference $(\mathrm{I})$.

A few crucial concepts have been displayed in Figure 1 , the point of variegation, the customer decoupling point and the point of provision. A black circle marks the point of variegation and represents the process step when the product embraces its final configuration, that is, where parts become dedicated to a product instance. This point is positioned by the patient in the as-is design of the supply chain. The point of provision, likewise, marked by a black circle, represents the position in the supply chain where the patient acquires the treatment. The customer decoupling point, marked by a black triangle, denotes the step when the demand for product variants is clarified. This demand is communicated by the physician in the form of patient prescriptions.

\section{Results}

This section discusses the results of executing the research activities presented in the Research approachsection. The collected operational performance criteria and the approach to performance assessment are described and the operational performance of the $a s$-is design in a customisation context is presented. The reconfigured supply chain designs are detailed and finally, the operational performance assessment of these designs is presented.

As mentioned, ambiguities in the entailed customisation level in a paradigm of personalised medicines remains. The level of customisation assumed in this study, for each customisation scenario discussed, is illustrated in Figure 3, with the nature of product variety labelled H-Customised, which visualises a type of pill organiser assembled before patient $\mathrm{C}$ acquires the prescription at the point of provision.

\section{The performance criteria and the approach to performance assessment}

The collected performance criteria are divided into five categories: the cost of operation, time-to-patient, quality assurance, degree of process change and value for the patient. Cost of operation covers the operational costs that can be translated into monetary values; time to patient measures the interval from diagnosis of the patient (i.e. when the physician writes a prescription) to treatment acquisition by the patient; quality assurance covers activities ensuring that product integrity is retained; degree of process change describes the reconfigurations required by the supply chain to enable operation in a reconfigured mode while value for the patient describes the patient benefit. The break-down and definitions of these categories are summarised in Table 1. The performance assessment approach follows the concept screening method by Ulrich and Eppinger (2012) where concepts are compared to a reference concept and for each criterion, $\mathrm{a}^{\text {' }}+$ ', ' '-'and ' 0 ' is assigned for the concept. A ' + ' indicates a favourable change, '- ' an unfavourable change and ' 0 ' indicates no change or a non-conclusive comparison when comparing the performance of the current concept to the reference concept. Finally, the net value, that is, the sum of ' - ': $\mathrm{s}$ deducted from the sum of ' + ' $: s$, is calculated to give an overall indication on the how well the concepts perform compared to the reference.

\section{The performance of the as-is design of the supply chain in a customisation context}

When assessing the performance of the as-is design in a customisation context, the supply chain design is kept intact. The position for H-Customised in the supply 
Table I. The performance criteria and the assessment of the as-is design operating in a customisation context.

\begin{tabular}{|c|c|c|c|}
\hline \multicolumn{2}{|l|}{ Performance criteria } & \multirow{2}{*}{$\begin{array}{l}\text { Definition } \\
\text { The utilisation level of the existing operational capacity }\end{array}$} & \multirow{3}{*}{$\frac{\text { Assessment }}{\overline{0}}$} \\
\hline Cost of operation & Capacity utilisation & & \\
\hline & Capital investments & $\begin{array}{l}\text { Any required capacity expansions in the supply chain } \\
\text { operation }\end{array}$ & \\
\hline & Inventory & $\begin{array}{l}\text { The stock levels of parts or products kept by the supply } \\
\text { chain actors }\end{array}$ & - \\
\hline & Material consumption & The consumption of diverse materials during operation & - \\
\hline & Economy of scale & $\begin{array}{l}\text { Cost advantages of producing higher volumes of product } \\
\text { variants }\end{array}$ & - \\
\hline \multirow[t]{2}{*}{ Time to patient } & Operational lead time & The time of operation & - \\
\hline & Delivery complexity & $\begin{array}{l}\text { The complexity of goods delivery to subsequent supply } \\
\text { chain actor }\end{array}$ & - \\
\hline \multirow[t]{2}{*}{ Quality assurance } & Effort in quality control & $\begin{array}{l}\text { Activities performed to ensure product quality in the } \\
\text { supply chain }\end{array}$ & - \\
\hline & Risk of errors & The risk of errors arising from operation & - \\
\hline \multirow[t]{2}{*}{$\begin{array}{l}\text { Degree of } \\
\text { process change }\end{array}$} & $\begin{array}{l}\text { New working procedures } \\
\text { within a supply chain node }\end{array}$ & $\begin{array}{l}\text { New technologies or activities required in the operation } \\
\text { of a supply chain actor, for example, the education or } \\
\text { technology needs to operate in a new context }\end{array}$ & - \\
\hline & $\begin{array}{l}\text { New working procedures } \\
\text { across nodes }\end{array}$ & $\begin{array}{l}\text { The level of operational alignment of the supply chain } \\
\text { operating in a customisation context with the supply chain } \\
\text { operating in an MP context }\end{array}$ & 0 \\
\hline \multirow{2}{*}{$\begin{array}{l}\text { Value for the } \\
\text { patient }\end{array}$} & Treatment outcome & The outcome of the treatment that the patient administers & + \\
\hline & Patient effort & $\begin{array}{l}\text { The effort required from the patient to achieve a certain } \\
\text { treatment outcome, for example, acquiring prescriptions, } \\
\text { splitting tablets and, any disregarded dosages due to } \\
\text { difficulty of swallowing the treatment }\end{array}$ & + \\
\hline$\Sigma+$ & & & 2 \\
\hline$\Sigma-$ & & & $\overline{9}$ \\
\hline$\Sigma 0$ & & & 2 \\
\hline The net value & & & -7 \\
\hline
\end{tabular}

chain coincides with product variety in position $\mathrm{H}$ in Figure 1 for the as-is design scenario (i.e. in an MP paradigm, the patient acquires a product of product variety level $\mathrm{H}$, while in a customisation scenario, the patient acquires a product of product variety level H-Customised). The resulting performance assessment when operating the as-is design of the supply chain in a customisation context is displayed in Table 1 and an explanation follows where each performance criteria, as well as the change to these, have been highlighted using bold text.

For the category cost of operation, each criterion results in unfavourable change except for capital investments, where no change is assumed. An increase in product portfolio complexity results in an increase in the number of changeovers during production, hence an increase in equipment downtime resulting in a decrease in capacity utilisation (Wilson, 2016). The as-is design is assumed to operate in alignment with the currently operating functions of the supply chain actors to the extent possible, and hence no change is expected in the criterion capital investments. An increase is expected for the criterion inventory, because although the stock levels per product might remain unchanged, an increase in the number of product variants requires additional stocks of these variants - increasing the inventory levels. An increase in material consumption is assumed due to the more diverse range of material purchases enabling the production of additional product variants. A consequential risk includes increased expirations of products, thereby accumulating waste and unnecessary material consumption (Price Waterhouse Coopers, 2011; Shah, 2004). For the economy of scale criterion, a decrease is expected, while economy of scale is achieved in an MP context by defining large patient segments (i.e. large groups of patients receiving the same treatment). In a customisation context, the economies of scale are challenged by a larger variety of smaller product volumes for smaller patient segments (Govender et al., 2020a; Wilson, 2016).

An unfavourable change is expected for time to patient when operating the supply chain in a customisation context due to the unfavourable change in operational lead time and delivery complexity. An increase in operational lead time is expected due to more frequently interrupted operational flow resulting from a larger product variety and additional handling and moving of parts and products (e.g. Stäblein, 2010; Trattner et al., 2019; Wilson, 2016). Delivery complexity is assumed to increase, because a more complex product portfolio is delivered in a customisation context instead of 


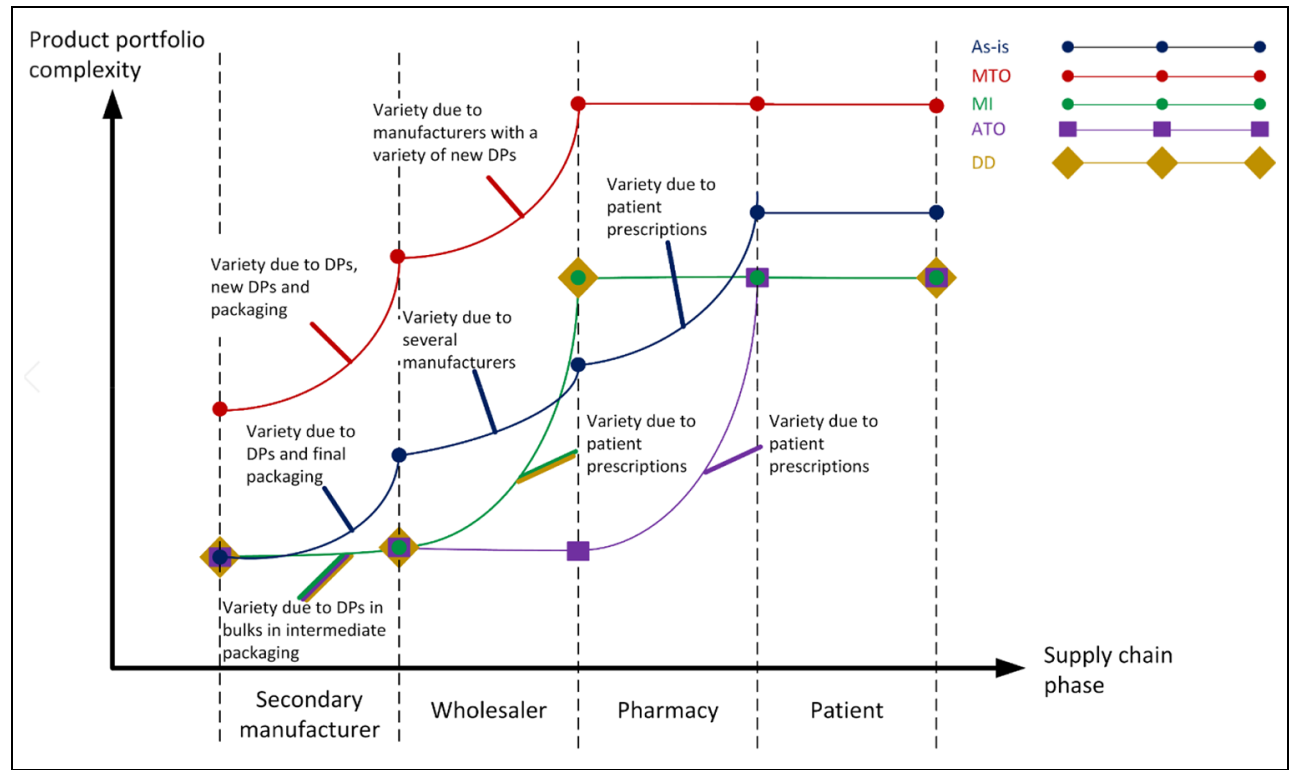

Figure 4. A conceptual sketch of the sources of variety in each supply chain scenario.

delivering large bulks of products to the subsequent supply chain actor.

An unfavourable change is expected for the quality assurance category. An increased effort in quality control is expected due to smaller batches, which increase the number of quality inspections since each batch requires quality assurance (Rantanen \& Khinast, 2015; Trattner et al., 2019). The risk of errors increases with the increasing number of processes, operations and work tasks to be managed throughout the supply chain (Trattner et al., 2019).

An unfavourable change is expected for degree of process change due to the criterion new working procedures within a supply chain node because a need for additional support tools and education is assumed to manage the increasing complexity of the product portfolio. No change is assumed for the criterion new working procedures across nodes since the as-is design of the supply chain is retained, and thus no new communication channels across nodes are established.

Value for the patient clarifies the benefit of personalised medicines, and Table 1 shows that a favourable change is expected for each criterion in this category. When operating the as-is design in a customisation context, it is assumed that the patient receives treatment according to their needs and preferences (product variety H-Customisation, see Figure 3), which increases the criterion treatment outcome. In addition, interference with the treatment before administration is disregarded thus making the activity finalise the assembly of DPS (5.3) in Figure 1 redundant and consequently also the arising product variety $I$. variety of patient interference.
This entails a decrease in patient effort since the treatment is matched to their needs and preferences without patient interference (Govender et al., 2020; Wilson, 2016).

To summarise the results of Table $1-$ a net value of -7 was obtained indicating that operating the as-is design of the supply chain in a customisation context is not a feasible solution. To acquire the benefits of producing customised pharmaceutical products, that is, to improve the treatment outcomes of the patients, consequences of operating the pharmaceutical supply chain are expected and challenge the transition to a paradigm of personalised medicines:

- Increasing costs, time to patient and effort in quality assurance activities.

- Increased degree of process change, that is, alternative technical solutions are required to enable managing the increased complexity of the product portfolio.

\section{Reconfigured supply chain designs for a mass customisation context}

Table 2 presents four reconfigured supply chain designs. In each scenario, the customer decoupling point aligns with the point of variegation which was not the case of operating the as-is design in an MP context. Four reconfigurations are presented: the MTO, MI, ATO and DD scenarios. The position of the point of variegation is varied in each scenario. 


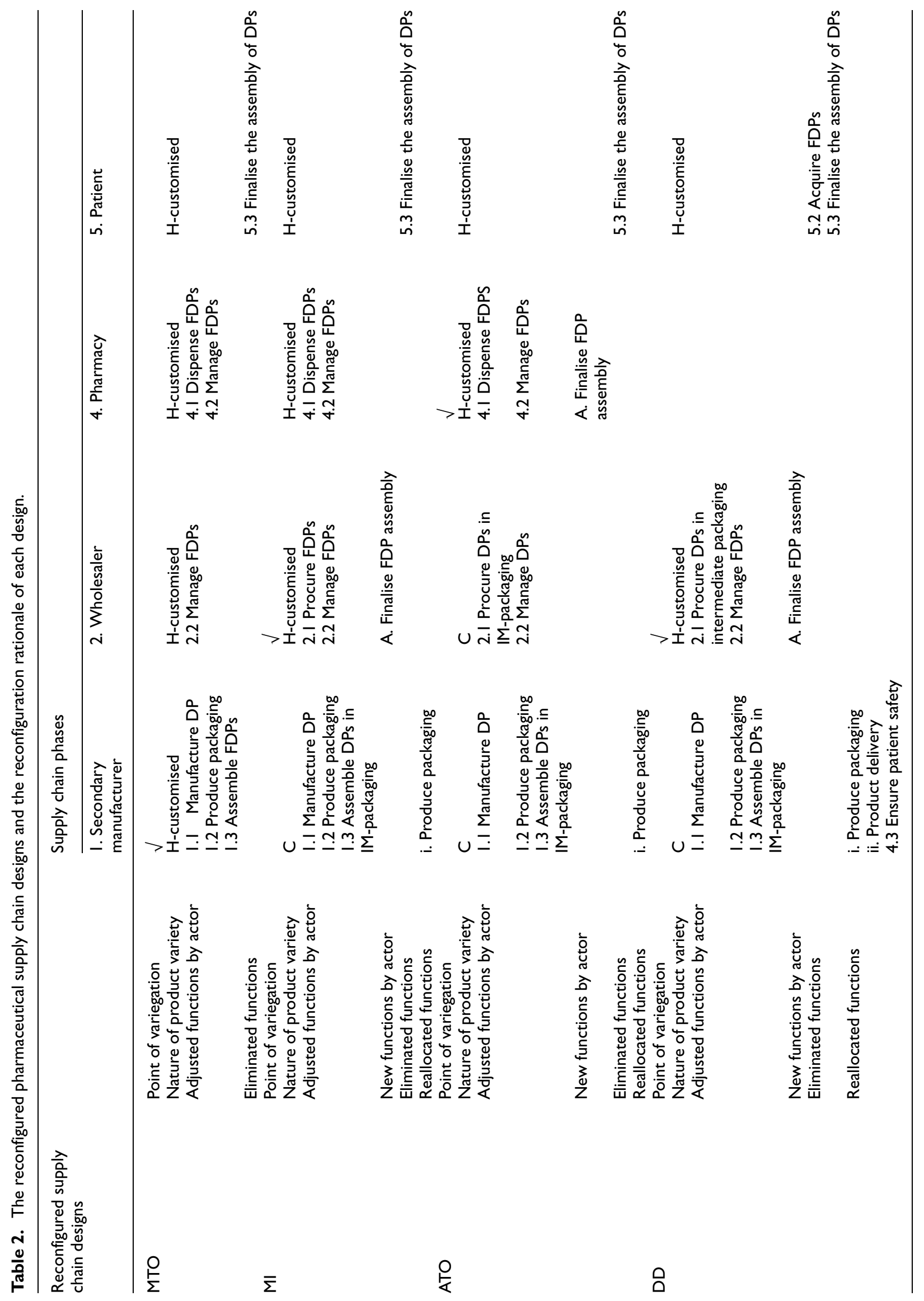


Table 3. The performance assessed for each reconfigured supply chain design as a comparison to the as-is design operating in a customisation context.

\begin{tabular}{|c|c|c|c|c|c|c|}
\hline Performance criteria & & $\begin{array}{l}\text { As-is design } \\
\text { customisation } \\
\text { context }\end{array}$ & MTO & MI & ATO & $\mathrm{DD}$ \\
\hline \multirow[t]{5}{*}{ Cost of operation } & Capacity utilisation & 0 & - & 0 & + & 0 \\
\hline & Capital investments & 0 & - & - & - & - \\
\hline & Inventory & 0 & + & + & + & + \\
\hline & Material consumption & 0 & + & + & + & + \\
\hline & Economy of scale & 0 & - & + & + & + \\
\hline \multirow[t]{2}{*}{ Time to patient } & Operational lead time & 0 & - & 0 & + & 0 \\
\hline & Delivery complexity & 0 & - & 0 & + & - \\
\hline \multirow[t]{2}{*}{ Quality assurance } & Effort in quality control & 0 & - & 0 & + & - \\
\hline & Risk of errors & 0 & - & 0 & + & - \\
\hline \multirow[t]{2}{*}{ Degree of process change } & $\begin{array}{l}\text { New working procedures } \\
\text { within a node }\end{array}$ & 0 & 0 & - & - & - \\
\hline & $\begin{array}{l}\text { New working procedures } \\
\text { across nodes }\end{array}$ & 0 & 0 & - & - & - \\
\hline \multirow[t]{2}{*}{ Value for the patient } & Treatment outcome & 0 & 0 & 0 & 0 & 0 \\
\hline & Patient effort & 0 & 0 & 0 & 0 & + \\
\hline$\Sigma+$ & & 0 & 2 & 3 & 7 & 4 \\
\hline $\bar{\Sigma}-$ & & 0 & 7 & 3 & 3 & 5 \\
\hline$\Sigma 0$ & & 13 & 4 & 7 & 3 & 4 \\
\hline The net value & & 0 & -5 & 0 & +4 & -1 \\
\hline
\end{tabular}

Table 2 marks the point of variegation with the symbol ' $\sqrt{ }$ '. The nature of product variety managed in each supply chain phase is displayed in Table 2 and is referenced by the labelling presented in Figures 1 to 3 within brackets, for example, (X). In addition, the evolution of the product portfolio complexity is displayed in Figure 4 and accompanied by product variety sources in each supply chain phase. The purpose of the sketch is to overview the product portfolio complexity for each scenario, and thus the absolute level of complexity for the scenarios has not been clarified, and the complexity levels are not to scale and not comparable in absolute values.

Any changes to the operational scope of the supply chain by the reconfigured designs are displayed in Table 2, and their numbering follows that of Figure 1. New activities required to be performed by the actors in the reconfigured mode are likewise displayed in Table 2 and subsequently discussed.

While reconfiguring the supply chain, the assumption is that the patient acquires a finalised customised treatment, nature of product variety (H-Customised), eliminating the need of patient interference with the product, similarly to the as-is design operating in an MC context. The function 5.3, finalise the assembly of DPs, is thus eliminated for each reconfigured design, which also eliminates any product variety arising from this activity, that is, I. variety of patient interference, as displayed in Figure 1.
The make to order scenario. The idea of the make to order (MTO) scenario is to create the final product variety, that is, performing the final assembly, where the assumed knowledge for this activity exists, that is, by the secondary manufacturer (the secondary manufacturer is assumed to be the most knowledgeable regarding drug production). No new activities are thus needed in the supply chain. The point of variegation is placed by the secondary manufacturer, and the physician is set to communicate directly with the secondary manufacturer, setting the demand for the product portfolio.

The difference between the MTO and as-is design is that in the MTO scenario, the market-ready prescriptions (H-Customised) are finalised by the secondary manufacturer according to patient needs, whereas in the as-is design scenario, the final bundling of product variants to satisfy the patient needs according to the prescription (H-Customised) occurs at the pharmacy. Thus, the secondary manufacturer must provide for any product variant required by a patient for any disease, which requires the secondary manufacturer to expand production to incorporate all treatments, adjusting 1.1 Manufacture DP, 1.2 Produce packaging and 1.3 Assemble FPs (also see Figure 4 for product portfolio complexity). This would also require a premade selection of the secondary manufacturer to produce the treatment, however, this consideration is outside the of this paper. No final bundling of 
prescription occurs at the pharmacy in the MTO scenario, the activity 4.1 dispense FPs is adjusted to solely cover the dispensation activity.

The secondary manufacturer in the MTO scenario must provide for any product variant as well as patient-specific packaging needs (H-Customised). Standardisations such as multipurpose packaging and information leaflets are not possible, which increases the final complexity of the product portfolio by the secondary manufacturer (nature of product variety $\mathrm{E}$ ) thus further, requiring the management of a product portfolio of increased complexity, 2.2 and 4.2, downstream the supply chain.

The manufacturer integrator scenario. The idea of the manufacturer integrator (MI) scenario is to bundle DPs from manufacturers early in the supply chain resembling the operating model of the retail corporation Walmart Inc. A standardised portfolio of DPs (C) is delivered from the secondary manufacturer to the wholesaler, who finalises the product assembly $(\mathrm{H}-$ Customised), A. finalise FDP assembly, after the prescription order by the physician has been placed and thus the activity 2.2 manage FDPs is adjusted. Furthermore, the production effort of the secondary manufacturer is reduced as bulks of DPs in intermediate packaging $(\mathrm{C})$ are produced rather than finalised FDPs thus, activities 1.2 and 1.3 are adjusted as well as the activity of final packaging production needs to be reallocated. In Table 2, the category 'reallocated functions' is displayed and lists the function $i$. produce packaging.

The position of the activity A. finalise FDP assembly at the wholesaler enables treating DPs with identical product formulation procured from various manufacturers as the same product variant - the activity 2.1 procure FDPs is adjusted. This decreases the number of variants in the product portfolio - eliminating the $\mathrm{N}$ dimension in the matrix for product variety $(\mathrm{F})$ (see Figure 2).

If the wholesalers operate in strategic positions close to the market the product portfolio complexity can be further reduced since the need to create packaging serving several markets is eliminated - eliminating the dimension denoted by the five-point star for product variety (E) in Figure 2. The complexity of the final product variety is thus lower for the MI scenario compared to the as-is design scenario (see Figure 4); however, the complexity of the product portfolio leaving the wholesaler is supposedly higher when comparing the MI to the as-is design scenario, because, in the latter, the patient-specific prescriptions have not yet been finalised.
Due to the pharmacy facing larger product variety in orders from the wholesaler in the MI scenario compared to the as-is design scenario, the managerial effort of the pharmacy is increased, 4.1, but the activity of final bundling various product variants according to patient-specific prescriptions is eliminated (which is the case in the as-is design of transforming $(\mathrm{F})$ into $(\mathrm{H}-$ Customised)).

The assembly to order scenario. The assembly to order (ATO) scenario simulates an environment where the final assembly is placed closest to the patient. The operating model of the restaurant franchise Subway resembles the ATO scenario, which includes the advantages of the MI scenario up to the point of the wholesaler; however, a later point of variegation placed by the pharmacy provides additional advantages such as managing a less complex product variety (C) further downstream the supply chain (bulks of DPs in intermediate packaging are managed throughout the supply chain to the pharmacy, see Figure 4). The strategic positions of pharmacies by the market served also eliminates the requirement of diverse packaging, thereby eliminating the source to variety denoted by a fivepoint star in Figure 2 for product variety (E).

The pharmacy can be characterised as a compounding pharmacy, transforming bulks of DPs in intermediate packaging (C) into prescription-ready orders of FDPs (H-Customised). Hence, the pharmacy operates a new activity $A$. finalise FDP assembly (see Table 2). Furthermore, a reallocation is required for the activity of providing for final packaging $i$. produce packaging. The communication channel of the actor providing for this activity is established towards the pharmacy.

The direct delivery scenario. In the direct delivery (DD) scenario, the point of variegation is placed by the wholesaler similarly to the MI scenario; however, direct delivery of the finalised, prescription-ready products to the point of the patient from the product configuration site is proposed. This design resembles the business model of the computer technology company Dell. A decreased effort by the patient is expected, thereby eliminating the function of 5.2 acquire FDPs. An alternative delivery channel for the products is, however, required, and a function ii. product delivery is displayed for 'reallocated activities' in Table 2.

Direct delivery to patients eliminates physical contact of the pharmacy with the product, which Table 2 displays as black cells by the pharmacy. The activity 4.3 ensure patient safety falls within the category 'reallocated functions' in Table 2 since this activity is crucial and hence, needs to be provided by other means. 
Operational performance of the reconfigured supply chain designs

The results from assessing the operational performance of each reconfigured supply chain design are presented in Table 3. As a reference concept, to which each reconfigured design has been compared, the as-is design has been used. For the performance criteria and the approach to performance assessment, a description is provided in the section titled "The performance criteria and the approach to performance assessment".

Cost of operation. Decreased capacity utilisation represents a consequence of an increased product portfolio complexity. For the MTO scenario, a higher product portfolio complexity throughout the supply chain results in lower capacity utilisation, thus, an unfavourable change is expected. For the MI scenario, the product portfolio complexity is assumed to surpass the as-is scenario at the wholesaler; however, to be surpassed by the $a s$-is scenario at the secondary manufacturer and the pharmacy. Hence, a non-conclusive comparison between the MI scenario and $a s$-is design is given in Table 3. The ATO scenario embraces a lower product portfolio complexity throughout the supply chain, and higher capacity utilisation is thus expected in the ATO scenario, resulting in a favourable change. The product portfolio complexity of the DD scenario follows the MI scenario up to the wholesaler. In the DD scenario, the capacity of the pharmacy is not needed, but there is a required capacity for delivering the products directly from the wholesaler to the point of provision. Hence, a conclusive comparison between the DD scenario and the $a s$-is design is not provided.

Considering the criterion capital investments, a need to invest in additional capacity at the secondary manufacturer for the MTO scenario is expected, resulting in an unfavourable change. The MI, ATO and DD scenarios are expected to require capital investments within the operations where new activities are introduced in the supply chain, such as the activity of $A$. finalise FDP assembly introduced in Table 2, likewise resulting in unfavourable changes.

Placing the customer decoupling point by the point of variegation, and early in the supply chain provides the best conditions to optimise production to the demand of product variants. A better match of production to this demand implies reduced inventory levels since safety stock is not needed to a similar extent, for example. Like inventory levels, a better match to the actual product demand is assumed to optimise material consumption and decrease risks of stock expiration. Hence, reduced inventory levels and material consumption are expected for the MTO, MI, ATO and DD scenarios, thus resulting in favourable changes for each scenario concerning these criteria.

Keeping the nature of product variety as bulks of DPs in intermediate packaging (product variety level C, see Figure 2) and regarding DPs similar in formulation as the same product variant is assumably conditioning achieving economy of scales. Larger volumes of fewer product variants characterise the MI, ATO and DD scenarios and results in favourable changes. In the MTO scenario, patient-specific product variety is created by the secondary manufacturer, which minimises the potential of achieving an economy of scale and thus an unfavourable change is expected for this criterion.

Time to patient. A decreased capacity utilisation is expected thereby also increasing the operational lead time. The same reasoning as for the criterion capacity utilisation, within the category cost of operation, thus applies for each reconfigured scenario. Due to the increased complexity of the product portfolio, a higher delivery complexity for the MTO scenario is expected. The resulting comparison provided between the MI and as-is design is non-conclusive with the same reasoning regarding the product portfolio complexity as for capacity utilisation. In the ATO scenario, a lower complexity is managed - bulks of DPs in intermediate packaging, and hence a favourable change is expected. The product complexity of the DD scenario behaves similarly to the MI scenario; however, the products are directly delivered from the wholesaler to the patient, significantly increasing the complexity of delivery to the point of provision and thus an unfavourable change is expected for this scenario.

Quality assurance. A product portfolio of increased complexity implies an increasing number of batches of lower volumes that need to be controlled for quality, thereby increasing the effort in quality control. An unfavourable change is thus expected for the MTO scenario. No conclusive comparison for the MI scenario is provided due to the indecisive comparison of the product portfolio complexity between the MI and $a s$-is design scenarios throughout the supply chain. The lower complexity of the product portfolio for the ATO scenario is expected to result in a favourable change for this criterion. In the DD scenario, the effort to control quality is assumed to be increased, resulting in an unfavourable change due to the new approach of product delivery to the point of provision. For each reconfigured supply chain design, the same reasoning for the criterion risk of error applies as in the criterion effort in 
quality control since this risk is increased with an increasing product portfolio complexity.

Degree of process change. As stated in Table 2, the function $A$. finalise FDP assembly is introduced to be operated by actors in the supply chain scenarios MI, ATO and DD. Introducing new functions is expected to result in an increased need for resources in the form of, for example, educational needs, re-shaping the organisations' operations and additional capital investments required for operation (also discussed under the criterion capital investments). This increase in resources is captured in the criterion new working procedures within a supply chain node and thus results thus in unfavourable changes for the MI, ATO and DD scenarios.

The criterion new working procedures across nodes is visible in Table 2 as the category 'reallocation of functions' and implies efforts required to enable realising the respective functions requiring reallocation, for example, the need of providing for customised packaging for the assembly process when moved to a supply chain position not already executing such an activity. Reallocation of functions is required for the MI, ATO and DD scenarios, thereby resulting in unfavourable changes for this criterion.

Value for the patient. In each supply chain scenario operating in a customisation context, the patient is offered a treatment embracing the product nature of $\mathrm{H}$ Customised (see Figure 3). Thus, the treatment outcome is the same in each supply chain scenario and thus no change is expected for this criterion. Risk of treatment misuse is possible after receiving the treatment before administration, but this is not considered here. The only scenario inducing a change in the criterion patient effort is the DD scenario due to eliminating the need for the patient to acquire their prescriptions at a pharmacy and instead receiving a direct delivery. Thus, a favourable change is expected for this criterion.

Summary of the results from the performance assessment. The results in Table 3 show that the ATO scenario displays the best performance compared to the $a s$-is design as a reference solution - the net value +4 . A later point of variegation provides for the strength of this scenario since a product portfolio of low complexity is managed throughout the supply chain. This implies decreased costs of operation, lead times and efforts towards quality assurance activities. However, the weaknesses of the ATO scenario are the requirement of new functions in the supply chain actors' operations and reallocated functions. The performance of the MI scenario results in the same net value -0 , as the $a s$-is design; however, this assessment is performed as a comparison to a single reference solution and without consideration of how well the scenarios perform in each criterion or their comparative importance. In addition, due to the trade-offs within the supply chain and the entailed comparison difficulty between the supply chain designs regarding the performance criteria, the results displayed in Table 3 represent an indication solely.

\section{Discussion}

To answer the first research question, RQ1, 'What are the operational weaknesses of the current pharmaceutical supply chain design when operated in a pharmaceutical product customisation context?' The results in Table 1 and the result analysis the section "The performance of the as-is design of the supply chain in a customisation context" shows that the inevitable increase in product portfolio complexity leads to increased costs in operation, time of supplying products to patients and efforts required for ensuring product quality. Furthermore, alternative solutions are required to enable managing the increased complexity of the product portfolio. The third research question, RQ3, 'How can the pharmaceutical supply chain be reconfigured to address the operational weaknesses of the currently operating supply chain' was posed to remedy the weaknesses elicited by RQ1. To answer RQ3 three key insights will be presented for consideration of supply chain reconfiguration:

Key insight 1: The position of the point of variegation is crucial to consider since it affects the final complexity of the product portfolio to be managed throughout the supply chain. A strategic position, close to the market, mitigates portfolio complexity by eliminating, for example, country-specific labelling or distinction between DPs with the same formulation but from different manufacturers (if placed by the wholesaler or later), scenarios ATO, MI and DD. According to Verhasselt and Friemann (2012), pharmaceutical product characteristics are largely identical for purely manufactured DPs from various manufacturers, and the increased complexity originates from the packaging of the DPs due to their need to display manufacturer brands. Furthermore, the position for the point of variegation divides the supply chain concerning operational performance. Phases before this point perform better compared to the phases following afterwards regarding the operational performance criteria capacity utilisation, economy of scale, operational lead time, effort in quality control and risk of errors. The complexity of the product portfolio grows in the point of 
variegation, hence, the later in the supply chain the point of variegation is placed, the better the overall performance concerning these abovementioned criteria, see scenario MI.

Key insight 2:Alignment with the currently operating supply chain design represents another parameter for consideration when reconfiguring the supply chain. Deviations require, for example, education of the supply chain actors to be able to operate the new design, capital investments into new technologies or capacities, ensuring safe product delivery to the patients and probable introductions of new communication channels with new supply chain actors. Overarching trade-offs integrating the operational and business levels require consideration. Improving operational performance, for example, by pushing the point of variegation to the point of provision (see the ATO scenario) results in an increased degree of process change, that is, a higher level of reconfiguration of the supply chain, meaning reallocating activities, introducing new activities, establishing new communication channels and so forth.

Key insight 3:Effort by the patient refers to the effort exerted by the patient to achieve the same treatment outcome and should incorporate the consideration of treatment acquisition, that is, if the patient acquires the prescription at the pharmacy or if the treatment is delivered to the point of the patient, that is, the DD scenario. Studies have shown concerns related to the rate of prescriptions acquired at the pharmacy; for example, a white paper by NEHI (the network for excellence in health innovation) in 2014 states that up to $30 \%$ of prescriptions for certain medications of first-time prescriptions are left on pharmacy shelves. The final assembly performed by the patient shall be considered. Reducing patient interference with the treatment is assumed to enhance the therapeutic outcome, verified by widespread research considering patient adherence and compliance, for example, Klingmann et al. (2020) and Hofmanová et al. (2020). In this study, each supply chain operating in a customisation context functions with the assumption that the patient acquires a fully customised product, with the consequence of increasing operational effort. A trade-off concerning the responsibility given to the patient regarding the final treatment assembly and the consequences on supply chain operations if eliminating patient interference shall be investigated.

To answer the second research question, RQ2, 'Which operational performance criteria can be used to assess the performance of the pharmaceutical supply chain operating in a customisation context?', the performance criteria were divided into five categories: cost of operation, time to patient, quality assurance, degree of process change and value for the patient, with the full set of criteria with respective definitions presented in Table 1 . This set represents initially suggested criteria for assessing the performance of pharmaceutical supply chain designs operating in a customisation context and is a result of literature studies as well as discussion with industrial practitioners. Due to the subjectivity of the selection of performance criteria, future studies to determine whether the correct criteria were collected is suggested.

The criteria were used to qualitatively assess the performance of the reconfigured supply chains and to solely capture a better or worse performance of the respective reconfigured supply chain design compared to the as-is design. As a method, the concept screening method by Ulrich and Eppinger (2012) was used. As a next step, a quantitative approach shall be considered for which Ulrich and Eppinger (2012) suggest the concept scoring matrix. In this method, the level to which the performance improves or worsens is assessed. In addition, the importance of each performance criteria is quantified by assigning weights to these. Improved comparisons between various supply chain designs could be achieved and support the choice of the bestperforming supply chain design. It is difficult to predict opportunities for testing supply chain reconfiguration in practice, but quantitative studies complemented with an ongoing dialogue with industrial practitioners might enhance the reconfigured supply chain designs.

The reconfigured supply chain designs were developed by studying successful business models beyond the pharmaceutical model, with a focus on those addressing customisation or a large product variety. A few business models were selected and adapted into the pharmaceutical product context to represent archetypes of reconfigured supply chain models. These archetypes were discussed with a group of industrial practitioners and thereby further refined. Better-suited business models for pharmaceutical products in a customisation context might have been overlooked.

The MC strategy postponement was addressed in this study. However, approaches integrating modular product architectures and reconfigurable manufacturing systems shall be considered for future work. Modular product architectures are advantageous from the perspective of providing variety for customers, however, the right level of modularisation shall be traded towards cost considerations. For example, Askhøj and Mortensen (2020) discuss the trade-off between part commonality and distinctiveness to find the right number of product architectures for a company and Borgue et al. (2019) discusses the trade-off between integral 
and modular product designs and their influence on costs. In addition, product division supports the approach to concurrent engineering (Prasad, 1999). Reconfigurable manufacturing systems shall be considered as an approach to improve the efficiency, as suboptimizing production seldom solves the complexity problem and thus, flexibility and reconfigurability into manufacturing systems are advocated (ElMaraghy et al., 2012).

This study uses the term personalised medicines for the physical treatment, that is, the tablet received by the patient, which is customised according to patients' individual needs and preferences. The term customised pharmaceutical product is used interchangeably with personalised medicines throughout the paper, and the level of intended customisation coincides with $\mathrm{H}$-Customised displayed in Figure 3. To further discussions on the terminology within the research field of personalised medicines and individualised treatment reader is referred to the works of Govender et al. (2020a).

\section{Conclusions and future work}

This study addresses the gap of no system-level, end-toend analysis of operating the pharmaceutical supply chain in a customisation context. The results show that operating the current pharmaceutical supply chain in a customisation context implies:

- Increasing costs, time to patient and efforts in quality assurance activities.

- An increasing degree of process change, that is, alternative technical solutions are assumed to be required to enable managing the increased complexity of the product portfolio.

To address these challenges, business models successfully managing high product variety or operating in an MC paradigm were studied, which inspired reconfigurations to the pharmaceutical supply chain. The MC principle of postponement as a product portfolio complexity mitigation strategy was used to adapt the business models into a pharmaceutical product context. Four reconfigured supply chain designs were suggested and constituted configurations with the point of variegation in varying locations of the supply chain. The performance of these supply chain reconfigurations was then assessed, with the results showing that:

- A strategically chosen position for the point of variegation can reduce product portfolio complexity.

- The position of the point of variegation causes trade-offs concerning performance within the supply chain.
- A trade-off between the level of customisation created prior to patient provision and the patient responsibility of performing the final customisation shall be considered.

- A trade-off between the degree of reconfigurations of the supply chain supporting an increased operational performance and keeping an alignment with the current design to reduce the need of capital investments in technology and education of supply chain actors shall be considered.

A qualitative performance assessment of the reconfigured supply chain designs has been performed, and conducting quantitative studies is suggested to generate knowledge regarding the feasibility of the designs. This paper studied the MC principle of postponement as a complexity mitigation strategy. Future studies should integrate product modularisation strategies and consider the flexibility of stakeholder operations required to manage a product portfolio of growing complexity in the pharmaceutical supply chain.

\section{Acknowledgements}

We would also like to acknowledge the steering team of the Astra Zeneca - Chalmers initiative supporting the work with industrial expertise.

\section{Declaration of conflicting interests}

The author(s) declared no potential conflicts of interest with respect to the research, authorship, and/or publication of this article.

\section{Funding}

The author(s) disclosed receipt of the following financial support for the research, authorship, and/or publication of this article: This work has been funded by the Chalmers University of Technology Foundation. This work has also been funded by the received stipend from the Göran Wallberg stiftelse to facilitate my stay at the Technical University of Denmark for 4 months to conduct this study, and this support is greatly appreciated.

\section{ORCID iDs}

Maria Siiskonen (iD https://orcid.org/0000-0001-8856-5724

Johan Malmqvist iD https://orcid.org/0000-0002-4689-4535

\section{References}

Ahmed S, Zhou Z, Zhou J, et al. (2016) Pharmacogenomics of drug metabolizing enzymes and transporters: Relevance to precision medicine. Genomics, Proteomics \& Bioinformatics 14(5): 298-313.

Aitken M (2016) Understanding the pharmaceutical value chain. Pharmaceuticals Policy \& Law 18(1-4): 55-66. 
Askhøj C and Mortensen NH (2020) Deciding on the total number of product architectures. Concurrent Engineering: Research \& Applications 28(1): 20-31.

Bhasin H (2019a) Business model of walmart - How does walmart make money? Marketing91. Available at: https:// www.marketing91.com/business-model-of-walmart/ (accessed 24 June 2020).

Bhasin H (2019b) Business model of Dell - How does Dell make money? Marketing91. Available at: https://www.marke ting91.com/business-model-of-dell/ (accessed 24 June 2020).

Borgue O, Panarotto M and Isaksson O (2019) Modular product design for additive manufacturing of satellite components: Maximising product value using genetic algorithms. Concurrent Engineering: Research \& Applications 27(4): 331-346.

Crommelin DJA, Storm G and Luijten P (2011) 'Personalised medicine' through 'personalised medicines': Time to integrate advanced, non-invasive imaging approaches and smart drug delivery systems. International Journal of Pharmaceutics 415(1): 5-8.

Derecque-Pois M (2010) How the role of the wholesaler has evolved in a complex supply chain. Pharma IQ. Available at: https://www.pharma-iq.com/market-access/articles/ how-the-role-of-the-wholesaler-has-evolved-in-a (accessed 12 January 2021).

ElMaraghy W, ElMaraghy H, Tomiyama T, et al. (2012) Complexity in engineering design and manufacturing. CIRP Annals 61(2): 793-814.

European Alliance for Access to Safe Medicines (n.d.) European supply chain complexity and confusion. Available at: https://eaasm.eu/public/downloads/ril6x/Patient_safety_report_FINAL + VERSION + p2.pdf (accessed 22 June 2020).

Govender R, Abrahmsén-Alami S, Larsson A, et al. (2020a) Therapy for the individual: Towards patient integration into the manufacturing and provision of pharmaceuticals. European Journal of Pharmaceutics and Biopharmaceutics 149: $58-76$.

Govender R, Abrahmsén-Alami S, Larsson A, et al. (2020b) Independent tailoring of dose and drug release via a modularized product design concept for mass customization. Pharmaceutics 12(8): 771.

Goyanes A, Robles Martinez P, Buanz A, et al. (2015) Effect of geometry on drug release from $3 \mathrm{D}$ printed tablets. International Journal of Pharmaceutics 494(2): 657-663.

Harrington TS, Phillips MA and Srai JS (2016) Reconfiguring global pharmaceutical value networks through targeted technology interventions. International Journal of Production Research 55(5): 1471-1487.

Hofmanová JK, Mason J and Batchelor HK (2020) Sensory aspects of acceptability of bitter-flavoured $7.5 \mathrm{~mm}$ filmcoated tablets in adults, preschool and school children. International Journal of Pharmaceutics 585: 119511.

$\mathrm{Hu}$ JS (2013) Evolving paradigms of manufacturing: From mass production to mass customization and personalization. Procedia CIRP 7: 3-8.

Klingmann V, Pohly CE, Meissner T, et al. (2020) Acceptability of an orodispersible film compared to syrup in neonates and infants: A randomized controlled trial. European Journal of Pharmaceutics and Biopharmaceutics 151: 239-245.
Kvist M (2010) Product family assessment. Doctoral Thesis. Department of Management Engineering, Technical University of Denmark, Lyngby, Denmark.

Landahl J, Jiao RJ, Madrid J, et al. (2020) Dynamic platform modeling for concurrent product-production reconfiguration. Concurrent Engineering: Research \& Applications. Epub ahead of print 30 October 2020. DOI: 10.1177/ 1063293 X20958938.

Lutz A (2014) 4 Reasons for subway's explosive growth. Business Insider. Available at: https://www.businessinsider.com/subway-business-strategy-2014-6? $\mathrm{r}=\mathrm{US} \& \mathrm{IR}=\mathrm{T}$ (accessed 24 June 2020).

Meyer UA (2004) Pharmacogenetics - Five decades of therapeutic lessons from genetic diversity. Nature Reviews Genetics 5(9): 669-676.

NEHI (2014) Ready for pick-up: Reducing primary medication non-adherence - A new prescription for health care improvement. A NEHI Issue Brief. Available at: https:// www.nehi.net/writable/publication_files/file/pmn_issue_brief_10_14_formatted_final.pdf (accessed 9 March 2021)

Norman J, Madurawe RD, Moore CMV, et al. (2017) A new chapter in pharmaceutical manufacturing: 3D-printed drug products. Advanced Drug Delivery Reviews 108: 39-50.

O'Connor TF, Yu LX and Lee SL (2016) Emerging technology: A key enabler for modernizing pharmaceutical manufacturing and advancing product quality. International Journal of Pharmaceutics 509(1-2): 492-498.

Olson L (n.d.) How does the pharmaceutical supply chain work? Learn the basics about the current pharmaceutical supply chain. Available at: https://www.datexcorp.com/ how-does-the-pharmaceutical-supply-chain-work/ (accessed 2 June 2020).

Prasad B (1999) Enabling principles of concurrency and simultaneity in concurrent engineering. AI EDAM 13(3): 185-204.

Prasad B (2016) On mapping tasks during product development. Concurrent Engineering: Research \& Applications 24(2): 105-112.

Price Waterhouse Coopers (2011) Pharma 2020: Supplying the future - Which path will you take? Pharma 2020 series. Available at: https://www.pwc.com/gx/en/pharma-lifesciences/pharma-2020/assets/pharma-2020-supplying-thefuture.pdf (accessed 9 March 2021)

Rantanen J and Khinast J (2015) The future of pharmaceutical manufacturing sciences. Journal of Pharmaceutical Sciences 104(11): 3612-3638.

Savage CJ, Roberts KJ and Wang XZ (2006) A holistic analysis of pharmaceutical manufacturing and distribution: Are conventional supply chain techniques appropriate? Pharmaceutical Engineering 20(4): 1-8.

Shah (2004) Pharmaceutical supply chains: key issues and strategies for optimization. Computers \& Chemical Engineering 28(6-7): 929-941.

Siiskonen M, Malmqvist J and Folestad S (2020) Integrated product and manufacturing system platforms supporting the design of personalized medicines. Journal of Manufacturing Systems 56: 281-295.

Srai JS, Harrington T, Alinaghian L, et al. (2015) Evaluating the potential for the continuous processing of 
pharmaceutical products-A supply network perspective. Chemical Engineering \& Processing: Process Intensification 97: 248-258.

Stäblein T, Holweg M and Miemczyk J (2010) Theoretical versus actual product variety: How much customisation do customers really demand? International Journal of Operations \& Production Management 31(3): 350-370.

Trattner A, Hvam L, Forza C, et al. (2019) Product complexity and operational performance: A systematic literature review. CIRP Journal of Manufacturing Science and Technology 25: 69-83.

Ulrich KT and Eppinger SD (2012) Product design and development. New York, NY: McGraw-Hill.
Verhasselt and Friemann (2012) Postponement strategies in pharmaceutical supply chains. Evaluation of costs and benefits. In: 23rd Annual Production and Operation Management Society (POMS) Conference, Chicago, IL, 27-30 April 2012. Chicago: Production and Operations Management Society (POMS).

Verrue C, Mehuys E, Boussery K, et al. (2011) Tablet-splitting: A common yet not so innocent practice. Journal of Advanced Nursing 67(1): 26-32.

Wilson MW (2016) Manufacturing platforms for patientcentric drug products. In: Stegemann S (ed.), Developing Drug Products in an Aging Society. 1st ed., Switzerland: Springer International Publishing, pp. 447-483.

\section{Author biographies}

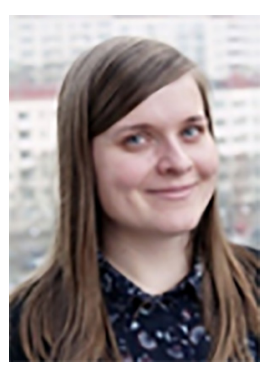

Maria Siiskonen is a $\mathrm{PhD}$ candidate at the Department of Industrial and Materials Science at Chalmers University of Technology in Gothenburg, Sweden. She received a master s degree from the same university in Chemical Engineering with Engineering Physics in 2015. Her research focuses on the feasible production of customized pharmaceutical products.

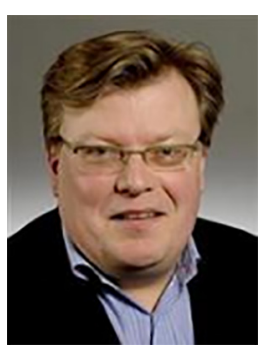

Niels Henrik Mortensen holds a PhD and an MSc in Mechanical Engineering and is employed as a Pprofessor at the Technical University of Denmark. He is head of the section of Engineering Design and Product Development at DTU Mechanical Engineering at the Technical University of Denmark. His main research focus is procedures and methods supporting development of Product Families based on Architectures and Platforms.

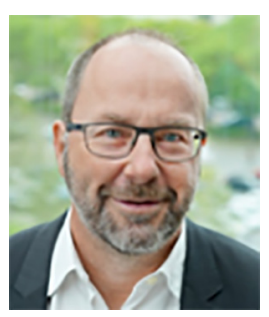

Johan Malmqvist is a Chair professor in Product Development at Chalmers University of Technology. His research addresses development methodologies and IT support for product development (PLM). Current research focuses on methods and tools for development of product-service systems, for product configuration and for strategic development of PLM solutions. Another area of interest is engineering education. Malmqvist was one of the cofounders and active in the international Conceive-Design-Implement-Operate (CDIO) Initiative, the engineering education model that has been developed by the CDIO Initiative has been adapted by a large number of across the world.

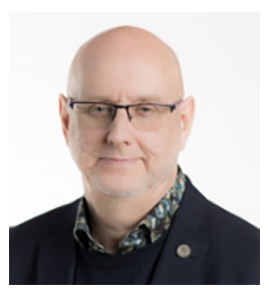

Staffan Folestad, Dr and associate professor (Swe Docent), is a director of Science \& Innovation at AstraZeneca with global responsibilities for Pharmaceutical Materials \& Manufacturing Sciences and Innovation Strategy and External Liaison. He is author of more than 140 scientific papers and book chapters in the areas of Continuous Pharmaceutical Manufacturing, in-silico Modeling, in-situ PAT Sensors, and novel Process Intensification Platforms. His current research activities are focused on Patient-Centric Pharmaceutical Product and Manufacturing Design approaches including unified solutions for Mass Customization/Mass Personalization. Among several external appointments he has trained PhD students (more than 20), is an elected member of the Royal Swedish Academy of Engineering Sciences (IVA), and is initiator of the pan-European science conference series EuPAT. In 2007 he received the "New Safe Medicines Faster Award" from the European Federation of Pharmaceutical Sciences. 